\title{
Enzymatic degradation of 3D scaffolds of starch-poly-( $\varepsilon$-caprolactone) prepared by supercritical fluid technology
}

\author{
Ana Rita C. Duarte ${ }^{\mathrm{a}, \mathrm{b}, *, 1,2}$, João F. Mano ${ }^{\mathrm{a}, \mathrm{b}, 1,2}$, Rui L. Reis ${ }^{\mathrm{a}, \mathrm{b}, 1,2}$ \\ a 3B's Research Group - Biomaterials, Biodegradables and Biomimetics, Dept. of Polymer Engineering, University of Minho, Headquarters \\ of the European Institute of Excellence on Tissue Engineering and Regenerative Medicine, AvePark, Zona Industrial da Gandra, S. Cláudio do Barco, \\ 4806-909 Caldas das Taipas, Guimarães, Portugal \\ ${ }^{\mathrm{b}}$ IBB - Institute for Biotechnology and Bioengineering, PT Associated Laboratory (Laboratório Associado), Portugal
}

\section{A R T I C L E I N F O}

\section{Article history:}

Received 18 April 2010

Accepted 22 June 2010

Available online 6 July 2010

\section{Keywords:}

Supercritical fluids

Starch

Polycaprolactone

Natural polymers

Enzymatic degradation

Tissue engineering

\begin{abstract}
A B S T R A C T
Starch-based polymers have been proposed for different tissue engineering applications due to their inherent properties. In this work, a polymeric blend of starch-poly-( $\varepsilon$-caprolactone) (SPCL) was processed using supercritical fluid technology, namely, by supercritical assisted phase inversion. As SPCL is a biodegradable polymer, the matrices produced are susceptible of undergoing enzymatic degradation upon implantation in the human body. In vitro assessment of the enzymatic degradation of SPCL was carried out in different buffer solutions containing $\alpha$-amylase and/or lipase. The effect of the presence of these enzymes was studied by monitoring different parameters in order to characterise both bulk and the surface of the scaffolds. As regards to bulk analysis, weight loss of the samples incubated for 1, 3, 7, 14 and 21 days was determined, further differential scanning calorimetry was carried out. The morphology of the scaffolds after these periods was analysed by micro-computed tomography ( $\mu$-CT) and surface chemistry was characterised by infra-red spectroscopy and contact angle measurements. Results suggest that SPLC scaffolds undergo bulk degradation, which is typically characterised by hydrolysis of chemical bonds in the polymer chain at the centre of the matrix, resulting in a highly porous material.
\end{abstract}

(c) 2010 Elsevier Ltd. All rights reserved.

\section{Introduction}

Starch-based polymers have been studied in our group for a wide range of bone-related therapy applications, ranging from tissue engineering scaffolds [1-4], to bone cements [5] and drug delivery systems [6,7]. Their natural origin, good mechanical properties, biocompatibility, biodegradability and hydrophilicity support the potential of these materials to be used for biomedical applications. Among these characteristics, biocompatibility plays a very important role as it determines the nature of the host response and graft survival. These nature-derived polymers have previously proved to be the right choice for these applications, mainly due to their low immunogenic potential and chemical/ biological versatility [8].

\footnotetext{
* Corresponding author. 3B's Research Group - Biomaterials, Biodegradables and Biomimetics, Dept. of Polymer Engineering, University of Minho, Headquarters of the European Institute of Excellence on Tissue Engineering and Regenerative Medicine, AvePark, Zona Industrial da Gandra, S. Cláudio do Barco, 4806-909 Caldas das Taipas, Guimarães, Portugal.

E-mail address: aduarte@dep.uminho.pt (A.R.C. Duarte).

1 http://www.3bs.uminho.pt

2 www.ibb.pt
}

The polymeric blend of starch and poly-( $\varepsilon$-caprolactone) (SPCL) takes advantages of the properties of natural-based polymers, particularly starch, which is one of the most abundantly occurring natural polymers and the synthetic polymer poly-( $\varepsilon$-caprolactone), a biodegradable aliphatic polyester currently used in an array of biomedical applications. Special attention should be paid to the degradation behaviour of the polymeric materials, as it can influence their in vivo performance. SPCL is a natural-based material, which may undergo hydrolysis. Hydrolysis reactions in this material can be accelerated in the presence of particular enzymes, such as $\alpha$-amylase and lipase. The enzymatic degradation process is affected by different variables and depends greatly on the interaction between the enzymes and the polymeric matrix. This process usually involves four steps: diffusion of the enzyme from the solution to the surface of the scaffold, enzyme adsorption, catalysis of the hydrolysis reaction and diffusion of the reaction products from the bulk of the matrix into solution [9].

The morphological properties of the scaffolds influence the rate of degradation as water uptake into the bulk of the scaffold is related with the porosity and topography of the 3D construct. In this work, SPCL scaffolds were produced using a clean and environmentally friendly technology, namely, supercritical fluid technology. Supercritical fluid technology has been proposed, in the 
past years, as an interesting alternative for the preparation of matrices for processing of biopolymers and biomedical devices [10-12]. The most relevant techniques described in the literature for the preparation of 3D scaffolds include gas foaming and phase inversion. The gas foaming technique is based on the plasticizing properties of carbon dioxide, which reduces the glass transition temperature of the polymers. Upon depressurization the thermodynamic instability created in system causes supersaturation of the carbon dioxide dissolved in the polymer matrix and hence, nucleation of cells occurs. Mooney and co-workers [13] were the first group to describe the use of a solvent-free technique for the preparation of porous sponges. After this work many others have been carried out and more recently special attention has been paid to applications in tissue engineering and regenerative medicine $[14,15]$.

The supercritical assisted phase inversion technique, on its turn, involves casting of a polymer solution onto an inert support followed by immersion of the support with the cast film into a high pressure vessel, which is then filled with a non-solvent for the polymer [16]. The contact between solvent and non-solvent causes phase separation. In the case of the supercritical assisted phase inversion the most commonly used non-solvent is carbon dioxide. The use of carbon dioxide has associated several advantages, for instance, the fact that simply by tuning the processing conditions, i.e., pressure and temperature, one can tailor the final structure of the product. Additionally, porosity and interconnectivity are induced in the samples at the same time that the material is precipitated from the organic solvent. The polymeric matrix is, therefore, recovered in the dry state, which avoids the use of any additional drying steps, reducing the processing energy consumption and leading to more efficient processes.

Supercritical assisted phase inversion has been described for the preparation of thin membranes from different synthetic polymers [16-19]. More recently this technique was successfully applied to the production of 3D scaffolds from natural-based polymers, for tissue engineering purposes. 3D chitosan structures have been processed from different organic solutions using this process [20,21]. Additionally, blends of starch/poly-L-lactic acid [22] and starch/poly-( $\varepsilon$-caprolactone) [23] have been processed using this green technology.

In this work, new scaffolds of SPCL are prepared using this technology and the enzymatic degradation of such structures is monitored. The propensity of the matrices prepared to be metabolized by physiological pathways is hereafter accessed and different techniques were employed to characterise not only surface but also bulk degradation.

\section{Experimental procedure}

\subsection{Materials}

Commercial blend of corn starch and poly-( $\varepsilon$-caprolactone) (SPCL), 30:70 wt\%, in granular form was used to perform the experiments. Chloroform, (CAS 67-68-5, 99.9\% purity) was purchased from Vaz Pereira. Carbon dioxide, (99.998 mol\%) was supplied by Air Liquide. All chemicals were used with no further purification.

The enzymes used in the degradation studies were $\alpha$-amylase (E.C. 3.2.1.1) from Aspergillus oryzae and lipase (E.C. 3.1.1.3) from Pseudomonas species purchased from Sigma.

\subsection{Supercritical assisted phase inversion process}

The phase inversion experiments were carried out in an apparatus especially designed for this purpose and presented in our previous work [22]. Briefly, a $15 \mathrm{wt} \%$ SPCL solution in chloroform is prepared. In each experiment a small amount (ca. $2 \mathrm{ml}$ ) of the polymer solution is loaded in a stainless steel cap with $2 \mathrm{~cm}$ diameter, which is placed inside the high pressure vessel. The vessel is heated in by means of an electric thin band heater (OGDEN) connected to a temperature controller, that maintains temperature within $\pm 1{ }^{\circ} \mathrm{C}$. Carbon dioxide is pumped into the vessel using high pressure piston pump (P-200A Thar Technologies) until the operational pressure is attained. The pressure inside the vessel is measured with a pressure transducer. The system was closed for 45 min to allow the occurrence of phase separation. Afterwards the system is flushed for another $45 \mathrm{~min}$, with a stream of carbon dioxide at very low flow rate $(5 \mathrm{~g} / \mathrm{min})$, in order to ensure complete drying of the scaffolds. The flow is regulated by a flow meter (Siemens, SITRANS FC MASS FLO MASS2100).

\subsection{Scaffold characterization}

Micro-Computed Tomography - $\mu$-CT: The inner structure, porosity and interconnectivity were evaluated by micro-computerized tomography using a Scanco 20 equipment (Skyscan 1702, Belgium) with penetrative X-rays of $40 \mathrm{keV}$. The X-ray scans were acquired in high-resolution mode. CT Analyser ${ }^{\circledR}$ was used to visualize the 2D X-ray sections images of the scaffolds.

\subsection{Water uptake and degradation}

The swelling capability of the prepared matrices was assessed by measuring the water uptake of the samples for a period up to 21 days. Pre-weighted SPCL scaffolds, prepared by supercritical phase inversion, were immersed in $10 \mathrm{~mL}$ of a phosphate buffer solution at $\mathrm{pH}=7.4$. The samples were placed in a water bath at $37^{\circ} \mathrm{C}$. After pre-determined periods of time $(1,3,7,14$ and 21 days $)$ the samples were weighted in order to determine the water uptake of the scaffolds.

Water uptake was determined using the following equation:

$\%$ water uptake $=\frac{w_{w}-w_{f}}{w_{f}} \times 100$

where $w_{w}$ is the weight of the wet sample and $w_{f}$ is the final weight of the sample (dried after immersion).

After each time period the samples were dried and weighted to determine the weight loss, which was calculated according to the equation:

$\%$ weight loss $=\left|\frac{w_{f}-w_{i}}{w_{i}}\right| \times 100$

where $w_{f}$ is the final weight of the sample (dried after immersion) and $w_{i}$ is the initial weight of the sample.

The $\mathrm{pH}$ of each solution was also measured in order to follow the release of acidic degradation products into the medium. The data presented is the result of the average of at least three measurements.

\subsection{Enzymatic degradation studies}

The enzymatic degradation of the SPCL scaffolds was investigated in three different solutions containing $\alpha$-amylase (150.5 U/l), lipase (102 U/l) and a solution containing both enzymes (150.5 U/l, $\alpha$-amylase and $102 \mathrm{U} / \mathrm{l}$, lipase), at $37^{\circ} \mathrm{C}$ and $60 \mathrm{rpm}$ up to 21 days. At the end of the pre-determined degradation times, the polymeric samples were dried at room temperature until constant weight. The final weight of the samples was used for the calculation of the 
weight loss (equation (2)). Experiments were performed in triplicate for all the conditions.

Fourier Transform Infra-Red analysis - FTIR analysis was performed to the scaffolds after 21 days of immersion in the enzymatic degradation solutions. The samples were powered, mixed with $\mathrm{KBr}$, and processed into pellets. Spectra were recorded at 32 scans with a resolution of $2 \mathrm{~cm}^{-1}$ (Shimadzu - IR Prestige 21 ).

Contact angle measurements - Surface properties of the matrices were assessed by means of static contact angle measurements using the sessile drop method with ultra-pure distilled water at room temperature. Contact angles were measured using a Contact Angle OCA +15 device (DataPhysics) and accompanying software SCA-20. The volume of the liquid droplets was kept constant at $1 \mu \mathrm{L}$ and at $1 \mu \mathrm{L} / \mathrm{s}$ rate. The results are the average of least three measurements.

Differential scanning calorimetry -DSC experiments were carried out using a DSC Q100 equipment (TA Instruments ELNOR). The experiments were conducted, under a nitrogen atmosphere, on samples (5-10 $\mathrm{mg}$ ) packed in aluminium pans. The samples were heated in two stages at a constant heating rate of $10^{\circ} \mathrm{C} / \mathrm{min}$ from room temperature up to $90^{\circ} \mathrm{C}$, then were left at this temperature for a period of $2 \mathrm{~min}$ and cooled at the same rate to the initial temperature. At this point a second heating run was conducted. Experiments were performed in triplicate and the results presented correspond to the average value ( \pm standard deviation).

\subsection{Statistical analysis}

Statistical analysis was performed to compare the degradation results between the samples immersed in the different enzymatic solutions. Two-way ANOVA with Bonferroni post test was performed using GraphPad Prism version 4.00 for Windows, GraphPad Software, San Diego California USA, www.graphpad.com. The results were considered statistically significant when $p<0.05$.

\section{Results and discussion}

Supercritical fluid technology, namely, supercritical assisted phase inversion technique was used for the preparation of $3 \mathrm{D}$ scaffolds of a polymeric blend of starch and poly-( $\varepsilon$-caprolactone). The SPCL constructs were prepared from a chloroform solution (15 wt\%) at 80 bar and $45{ }^{\circ} \mathrm{C}$. A macroporous structure homogeneous throughout all the volume with high porosity and interconnectivity was produced. Fig. 1 represents a 2D image of the SPLC matrices prepared at 80 bar and $45^{\circ} \mathrm{C}$ as well as the 3D model of the sample.

The precipitation of SPCL matrices by supercritical assisted phase inversion leads to a bi-continuous structure, characterised by the existence of macropores ( $>200 \mu \mathrm{m}$ ) and also micropores. More details on the pore size and total porosity will be given later. The mechanism proposed for the production of this type of interconnected structures is spinodal decomposition. However, another hypothesis has been raised to describe the behaviour observed, which states that the bi-continuous structures are a result of coalescence of polymer poor droplets generated by binodal decomposition [24,25].

\subsection{Water uptake and degradation studies}

Both the hydration degree and the degradation behaviour are two important properties of the materials when they are aimed to be used in biomedical or environmental applications, as their life time will be governed by these two processes which are intimately correlated. For biodegradable polymers, degradation occurs as a result of natural biological processes such as hydrolysis. Water uptake of the SPCL porous structures prepared by supercritical assisted phase inversion was evaluated for samples immersed in PBS solution for different time periods. Fig. 2 presents the percentage of water uptake of the matrix as a function of time.

A great fraction of the water uptake corresponds to the water that is absorbed in the macropores of the scaffolds. The limit value for the water uptake should be regarded as a result of two complementary phenomena: the intrinsic water uptake capability of the material (related to the chemical composition and crystallinity) and the porosity of the material. Scaffolds prepared by different processes, namely SPCL scaffolds prepared by fibre bonding have been reported in the literature [2] and exhibit similar water uptake profiles to the ones presented in this work. This can be explained due to the similarities in porosity and interconnectivity of the 3D matrices, which are $64 \%$ and $65 \%$, respectively.

The morphological properties of the 3D scaffolds have a relevant role in the swelling and degradation of the matrix. After implantation, biomaterials interact with surrounding fluids by first absorbing water, which initiate their degradation process. The absorption of water makes the material more flexible and might cause dimensional changes. Moreover, higher water absorption usually accelerates the hydrolysis process. The scaffolds' porosity will have direct influence in the ease of retention and access of the degradation solution in the bulk of the material, which will therefore influence their degradation behaviour. During degradation, the mass of the material may undergo changes and these changes can be monitored by comparison of the mass before and after the degradation period.

An intrinsic characteristic of natural polymers is their ability to degrade by naturally occurring enzymes, which are present in the serum [9]. Therefore is of particular interest to study the enzymatic degradation of SPCL scaffolds prepared by supercritical assisted
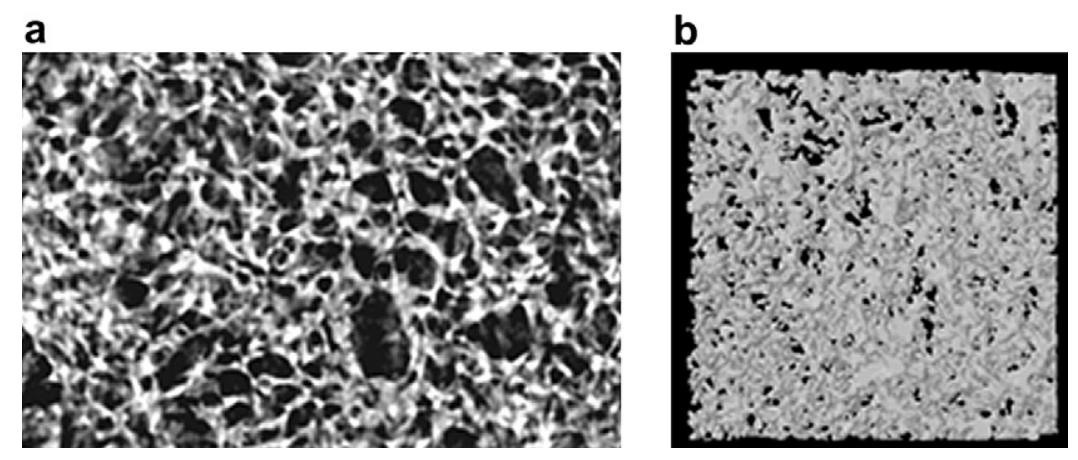

Fig. 1. Representative Micro CT images of SPCL matrices prepared at 80 bar and $45^{\circ} \mathrm{C}$ : a) 2D surface and b) 3D model. 


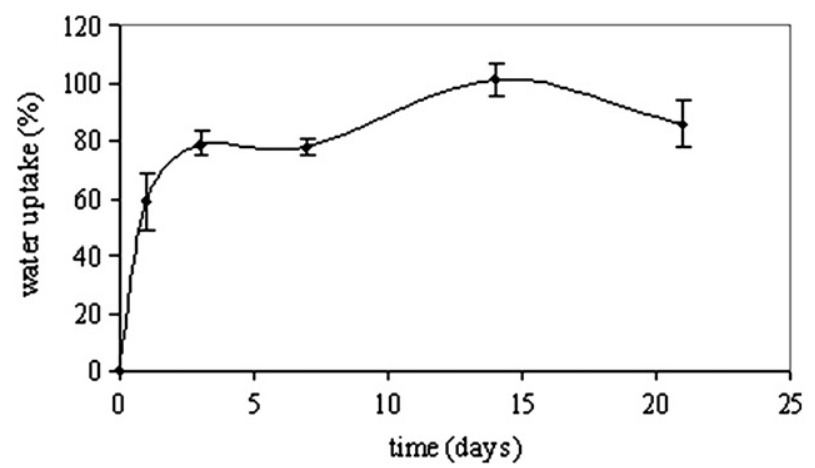

Fig. 2. Water uptake profile of SPCL porous scaffolds prepared by supercritical phase inversion $\left(80\right.$ bar and $45^{\circ} \mathrm{C}$ ) immersed in PBS solution.

phase inversion. Starch is essentially a linear polymer composed by glucose units bonded by $\alpha(1-4)$ glycosidic links. $\alpha$-amylase is an enzyme that catalyses the hydrolysis of glycosidic bonds, reducing the molecular weight of starch. On the other hand, hydrolysis of poly-( $\varepsilon$-caprolactone), an aliphatic polyester can be catalysed by lipase which hydrolytic action is targeted on the ester carbonyl group (Scheme 1) [26-28].

The enzymatic degradation of SPCL scaffolds was also assessed in this work. Fig. 3 shows the weight loss of the material immersed, in different solutions, as a function of time.

From Fig. 3 it is possible to conclude that most degradation occurs within 3 days of immersion on the different solutions. This is consistent with the time scale of water uptake as observed in Fig. 2. The diffusion of water into the bulk of the matrix weakens the structure, which is susceptible to a faster degradation. As it can be observed the weight loss of SPCL samples immersed in a solution containing $\alpha$-amylase + lipase is greatly accelerated. On the contrary, the presence of $\alpha$-amylase alone does not induce a faster degradation when compared to the control with PBS. Comparing the effect of $\alpha$-amylase and lipase alone we can conclude that lipase induces a faster degradation of the polymer. The work reported by Paskhuleva et al. indicates that a higher degradation rate is related with the distribution of the two polymers in the blend [29]. The presence of PCL on the surface of the scaffold makes it more susceptible to degradation by lipase, which justifies the faster degradation rate of the samples immersed in lipase solution. After 7 days of immersion minor changes were observed in the swelling and in the weight loss of the polymer within the time range analysed.

One of the effects of polyester hydrolysis, i.e., the cleavage of carboxylic groups of poly-( $\varepsilon$-caprolactone), is the change in the acidity of the media. Therefore it was also expected that the $\mathrm{pH}$ of these solutions would decrease. In Fig. 4 it is represented the trend of the $\mathrm{pH}$ of the media as polymer degradation occurs.
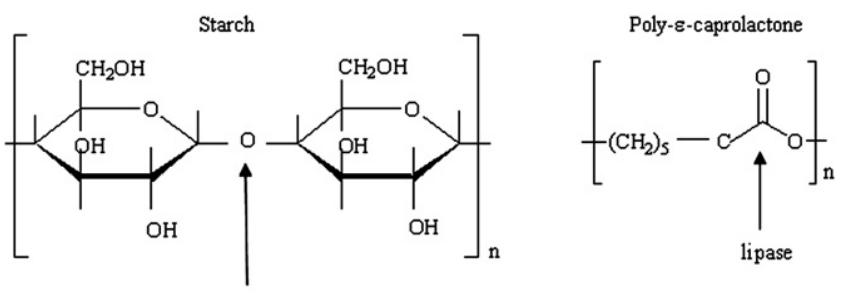

$\alpha$-amylase

Scheme 1. Molecular structure of starch and poly- $\varepsilon$-caprolactone (arrows indicate bonds for $\alpha$-amylase and lipase cleavage, respectively).

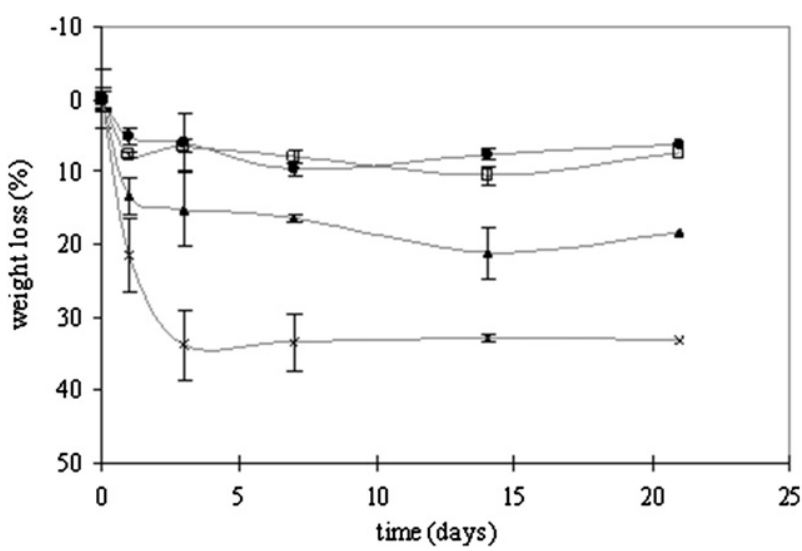

Fig. 3. Weight loss profile of SPCL porous scaffolds prepared by supercritical phase inversion immersed in different solutions ( $\bullet-$ PBS; $\square-\alpha$-amylase; $\boldsymbol{\Delta}-$ lipase; $\mathrm{x}$ $-\alpha$-amylase + lipase).

Samples immersed in the solution containing lipase and the mixture $\alpha$-amylase + lipase were the ones that suffered a faster degradation rate, therefore, it is observed an accentuated decrease on the $\mathrm{pH}$ of these solutions.

Morphological analysis of the samples after degradation was performed by $\mu$-CT. Micro-CT allows an objective comparison between samples since the porosity, interconnectivity and pore size distribution can be calculated.

The interconnectivity of the scaffold is calculated according to the formula: $I=\left[\left(V_{\text {totalpore }}-V_{\text {disconnectedpore }}\right) / V_{\text {totalpore }}\right] \times 100$, where the volume of the disconnected pore stands for the disconnected pore volume which was defined to be higher than $50 \mu \mathrm{m}$.

Figs. 5a, b and 6 represent the enzymatic degradation effect on the porosity, interconnectivity and pore size distribution, respectively. These analyses were performed with samples immersed on lipase and $\alpha$-amylase + lipase solutions as these were the ones that presented a faster degradation.

Scaffold degradation greatly influences the morphology of the materials. As enzymatic degradation occurs the porosity of the samples increases, indicating that degradation occurs not only at the surface of the material but also in the bulk of the matrix. For this reason interconnectivity of the samples also increases. From this analysis, and as expected, indeed we observed an increase in the

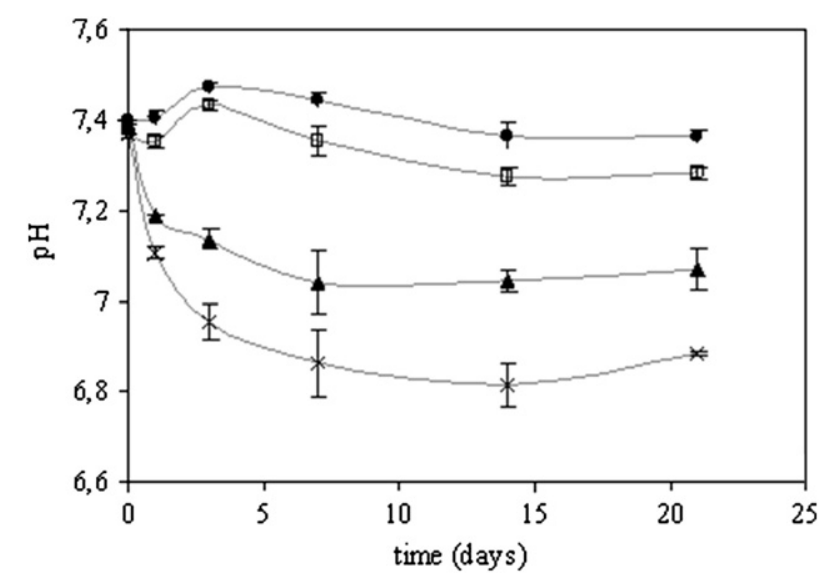

Fig. 4. $\mathrm{pH}$ profile of the solutions ( - PBS; $\square-\alpha$-amylase; $\boldsymbol{\Delta}-$ lipase; $\mathrm{x}-$ $\alpha$-amylase + lipase) where the SPCL porous scaffolds, prepared by supercritical phase inversion, were immersed. 

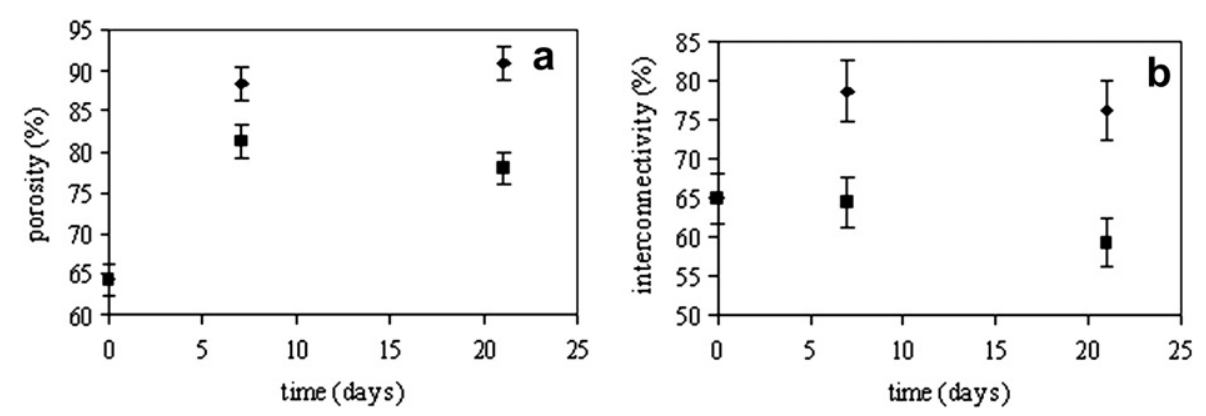

Fig. 5. Degradation effect on the a) porosity and b) interconnectivity of the SPCL scaffolds; ( $\boldsymbol{\square}$ lipase; $\bullet \alpha$-amylase + lipase).

porosity and interconnectivity of the samples as the degradation takes place. Another consequence is related with the pore size distribution, which is shifted towards larger pore sizes as immersion time increase.

Micro CT reconstruction of the 3D scaffolds after immersion illustrates the changes observed in the materials. Fig. 7 shows the model for the SPCL samples after 7 and 21 days of immersion in lipase and $\alpha$-amylase + lipase solutions, respectively.

The chemical modifications, which occur during the enzymatic degradation process, can be evaluated by FTIR spectroscopy. Fig. 8 represents the spectra of SPCL scaffolds immersed in enzymatic solutions for a period of 21 days and for the control, in PBS solution.

The starch band correspondent to the $-\mathrm{C}-\mathrm{O}-\mathrm{C}-$ glycosidic bond is reported in the literature to be $\left.1150-1040 \mathrm{~cm}^{-1}{ }^{* *}\right)$ [30]. The characteristic peak of PCL, which corresponds to the $\mathrm{C}=\mathrm{O}$ stretch ester carbonyl group is $1740 \mathrm{~cm}^{-1}\left({ }^{*}\right)$. From Fig. 8 we can evaluate the effect of enzymatic hydrolysis on the chemical structure of the matrices. A decrease in the intensity of the band 1150-1040 $\mathrm{cm}^{-1}$ was observed for the sample immersed in $\alpha$ amylase solution, which indicates the cleavage of the glycosidic bonds of starch. The reduction of intensity on the $1740 \mathrm{~cm}^{-1}$ peak confirmed the action of lipase on the hydrolysis of the ester bonds of PCL. When samples were immersed in a solution containing both enzymes the differences are not so noticeable. This observation might be explained due to the heterogeneous distribution of starch and PCL in the blend. Nonetheless from the evaluation of the weight loss we can conclude that the enzymes are hydrolysing both components of the polymeric blend.

As degradation takes place and the polymer blend undergoes chemical modifications due to the presence of enzymes, the surface properties of the material may also change. For instance, hydrophilicity of the samples might change as an inherent result of the cleavage of certain bonds of PCL. Fig. 9 represents the contact angle measurements performed for the samples immersed for 21 days in
PBS, lipase and $\alpha$-amylase + lipase solutions. The contact angle of SPCL samples not immersed (control) is shown for comparison.

From these results we can observe a clear change in the hydrophilicity of the scaffolds. Initial samples present a hydrophobic character, which can be attributed to the high PCL content in the blend $(\sim 70 \%)$. When the material is immersed in a solution containing lipase, PCL is degraded and the samples become more hydrophilic due to the presence of terminated carboxylic groups. This effect is not so pronounced in the case of the samples immersed in $\alpha$-amylase + lipase solution as in this case, both starch and PCL are degraded.

Differential scanning calorimetry provide qualitative and quantitative information about physical and chemical changes that involve endothermic or exothermic processes or changes in heat capacity. More specifically, the melting and crystallization temperature and melting enthalpy of the polymer can be obtained. DSC of the raw and processed material was also carried out to control the effect of any changes in the polymer prior to degradation. Fig. 10 shows the first heating scan of SPCL before and after being processed by supercritical assisted phase inversion.

The difference observed in the DSC data have been observed in other studies reporting the use of supercritical fluid technology in the preparation of PVDF membranes [31]. Supercritical assisted phase inversion enhanced the crystallization development of the polymer, which is evident in the DSC trace. Compared to the raw material, both the crystallinity and melting enthalpy of the SPCL scaffolds produced are higher.

Fig. 11a, b represent the DSC first and second heating run, respectively, for samples immersed for 21 days in PBS, $\alpha$-amylase, lipase and $\alpha$-amylase + lipase. A summary of the results obtained is presented in Table 1).

Degradation of the material may induce differences in the thermal response of the polymers [31,32]. The statistical analysis of the results obtained allows the depiction of some conclusions.
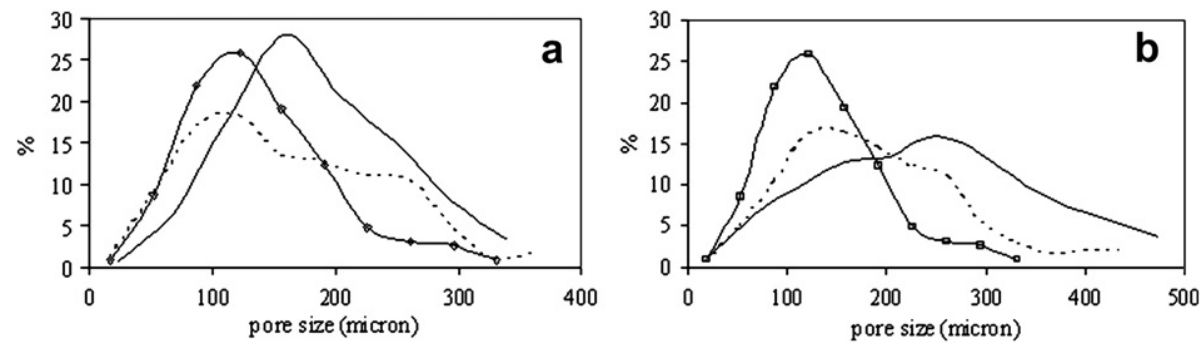

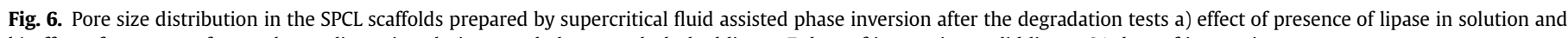
b) effect of presence of $\alpha$-amylase + lipase in solution: symbol - control; dashed line -7 days of immersion; solid line -21 days of immersion. 


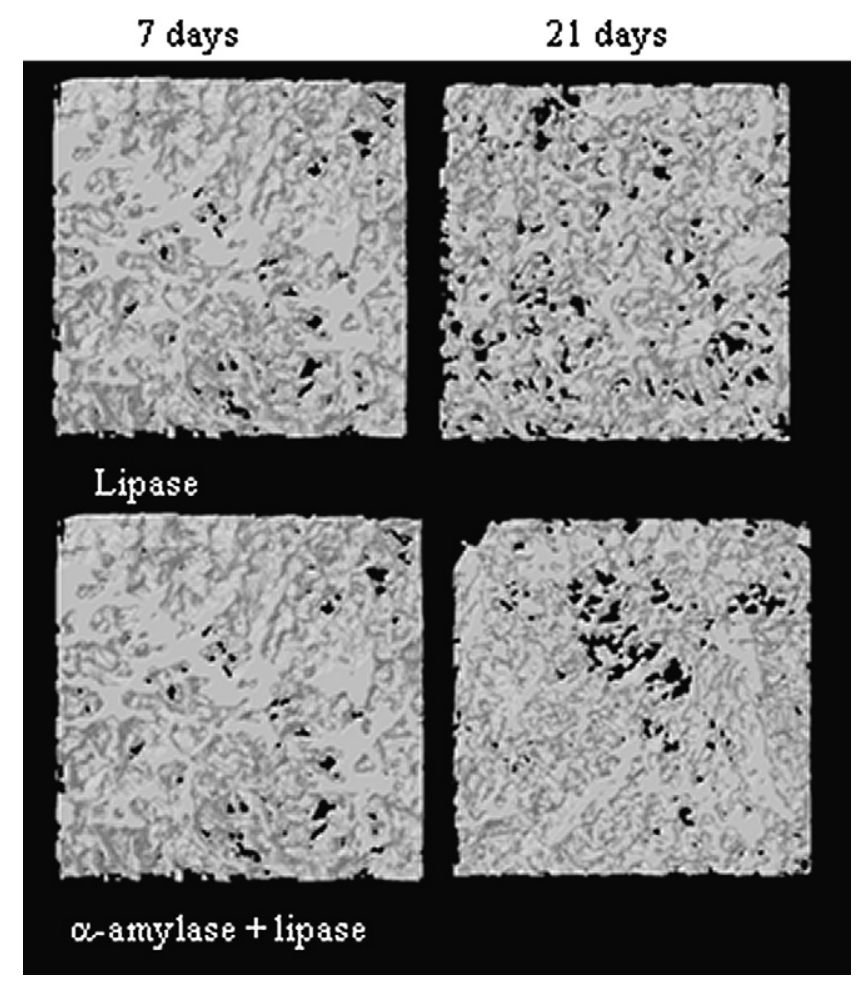

Fig. 7. 3D model of SPCL scaffolds prepared by supercritical fluid assisted phase inversion after 7 and 21 days of immersion in lipase and $\alpha$-amylase + lipase solutions

The melting temperature of the SPCL scaffolds is significantly affected by the immersion time as well as by the immersion solution $p<0.05$. The presence of a shoulder in the first heating scan might be due to the melting of small crystals formed during processing. For the same reason, a shift towards lower temperatures on the melting peak of the degraded samples is observed, especially in the samples immersed in PBS and $\alpha$-amylase.

Extremely significant differences were observed in the melting temperature obtained in the first and second run of the DSC. While the $T_{\mathrm{m}}$ calculated from the first heating run is $\sim 63{ }^{\circ} \mathrm{C}$ the $T_{\mathrm{m}}$ determined from the second scan is $\sim 53{ }^{\circ} \mathrm{C}$. This change in melting temperature reflects the completely different conditions in which crystallization took place in the two cases. It seems that the

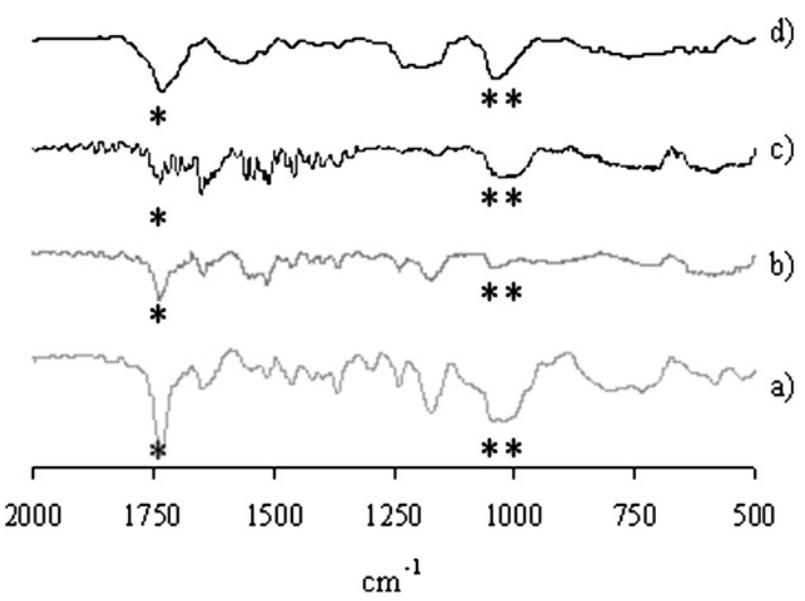

Fig. 8. FTIR spectra of SPCL scaffolds after 21 days immersion in a) PBS; b) $\alpha$-amylase; c) lipase and d) $\alpha$-amylase + lipase solution.

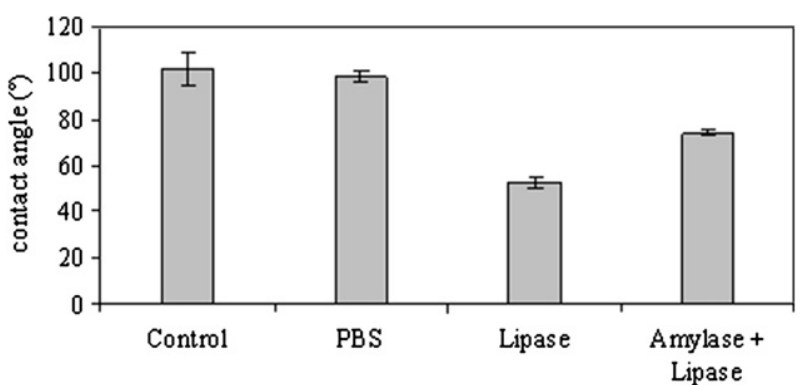

Fig. 9. Contact angle of SPCL samples immersed for 21 days in PBS, lipase and $\alpha$ amylase + lipase (SPCL sample not immersed is also shown as control).

crystalline structure formed during supercritical assisted phase inversion processing is characterised by thicker lamellae as compared to the ones resulting from the crystallization inside the pans during the cooling process prior to the second scan [33].

The analysis of the crystallinity was carried out in all the materials subjected to degradation. The crystallinity of the PCL fraction in the sample $(X)$ was calculated from equation (3):

$X=\frac{\Delta H_{m}}{\Delta H_{m}^{0} \cdot w} \times 100$

Where, $\Delta H_{m}$ is the specific melting enthalpy of the sample, $\Delta H_{m}^{0}$ is the melting enthalpy of $100 \%$ crystalline poly-( $\varepsilon$-caprolactone) (139.5 J/g [34]), and $w$ is the weight fraction of PCL in the blend, which is $70 \%$ wt. The crystallinity of the materials is affected by its degradation. In Fig. 12 the variations of polymer crystallinity as a function of degradation time are represented.

In semi-crystalline polymers, an increase in crystallinity is often observed at the early stages of degradation. This behaviour has been observed for different polymers and is related to two effects. On one hand, increase in crystallinity degree is consistent with the reduction in amorphous content as initial hydrolysis takes place preferentially at the amorphous regions, which are more accessible to both water molecules and enzymes. On the other hand, the plasticizing effect of water uptake increases chain mobility and therefore, crystallization proceeds towards thermodynamic equilibrium [9]. The lower molecular weight polymeric segments resulting from this degradation in the amorphous phase may partially organize into new crystalline structures, increasing the crystalline fraction of the material. As degradation takes place the cleavage of the polymeric chains by the action of the enzymes present in the buffered solution, lead to a diminishing of crystalline regions, thus the overall crystallinity of the scaffold decreases.

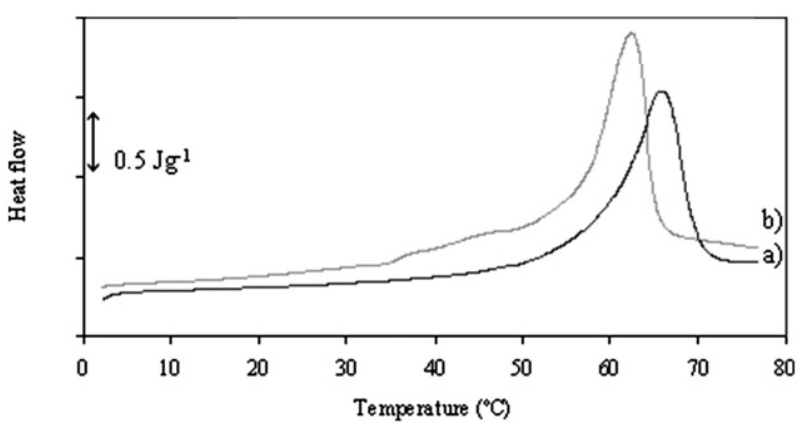

Fig. 10. DSC first heating run of SPCL a) raw material and b) processed at 80 bar and $45^{\circ} \mathrm{C}$. 

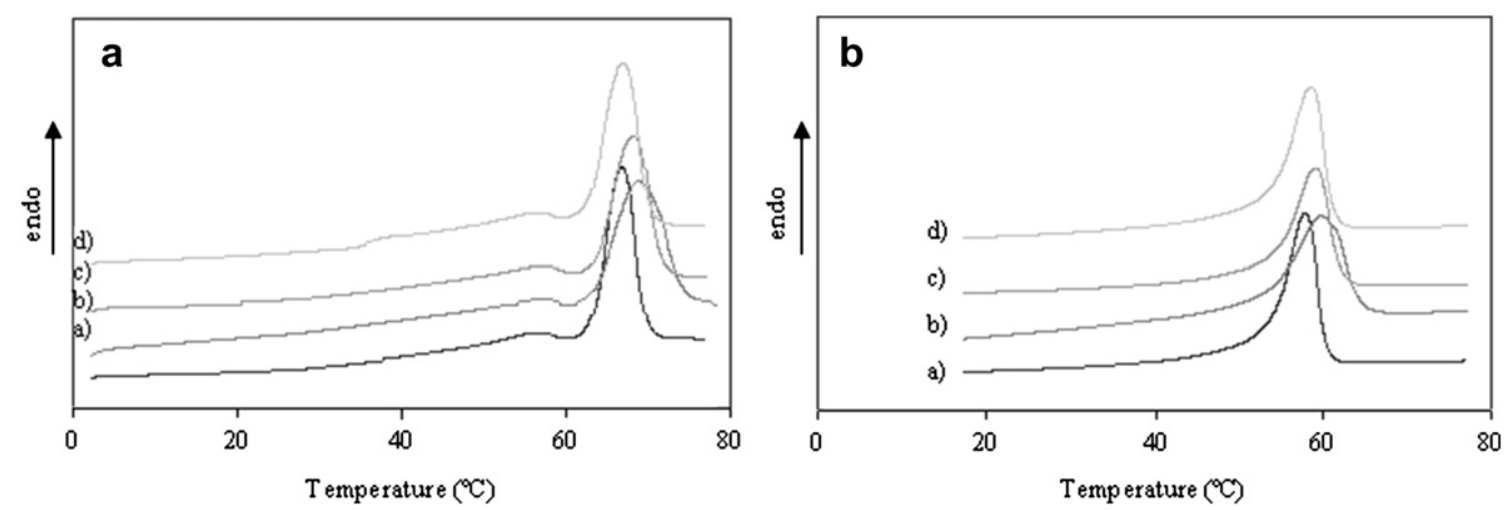

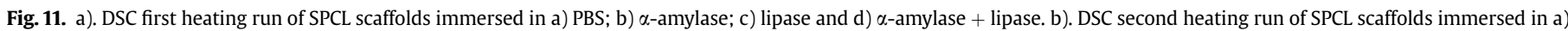
PBS; b) $\alpha$-amylase; c) lipase and d) $\alpha$-amylase + lipase.

Table 1

DSC data and crystallinity of SPCL scaffolds after degradation.

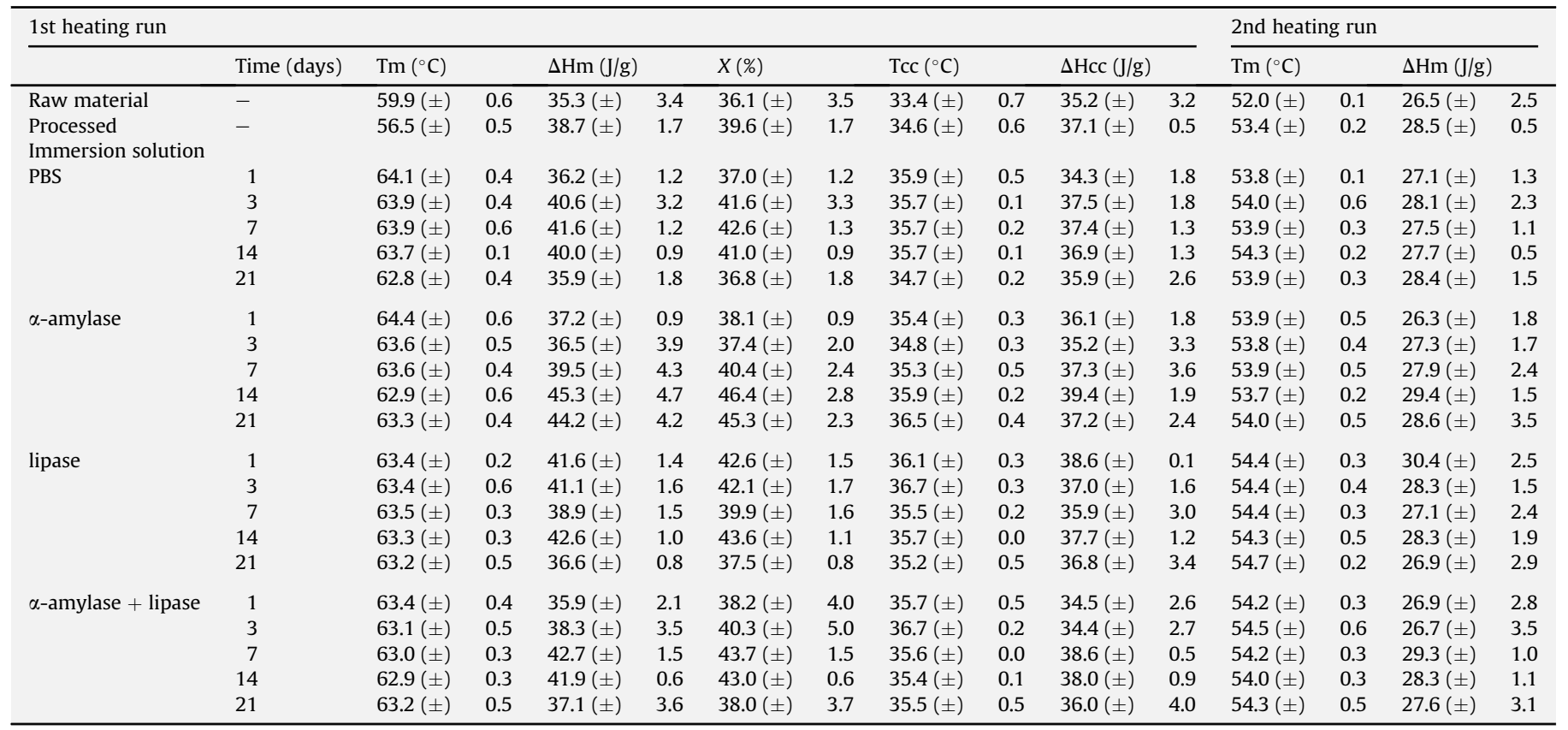

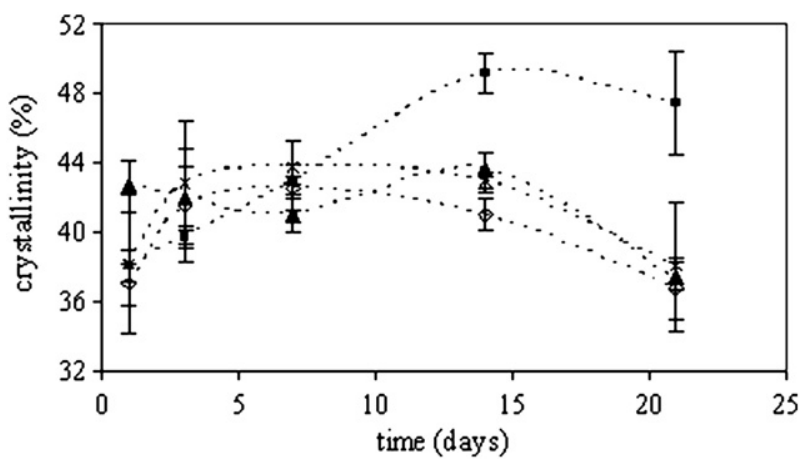

Fig. 12. Crystallinity of SPCL scaffolds prepared by supercritical phase inversion ( 80 bar and $45^{\circ} \mathrm{C}$ ) immersed in different solutions ( $\diamond-$ PBS; $\boldsymbol{\square}-\alpha$-amylase; $\boldsymbol{\Delta}-$ lipase; $\mathrm{x}-\alpha$-amylase + lipase $)$ as a function of immersion time.

\section{Conclusions}

A starch-poly-( $\varepsilon$-caprolactone) blend (SPCL) was processed by supercritical assisted phase inversion. A 3D scaffold, highly porous and interconnected with potential applications in tissue engineering was produced.

Biodegradable polymers, such as SPCL are susceptible to hydrolysis in aqueous solutions. For this reason, and particularly important in materials for biomedical applications is the study of the in vitro polymer degradation. Starch and poly-( $\varepsilon$-caprolactone) suffer enzymatic hydrolysis from $\alpha$-amylase and lipase, respectively. From this work it is possible conclude that the presence of $\alpha$-amylase alone did not enhance the degradation when compared to the control in PBS solution. On the contrary, the presence of lipase accelerates the degradation process and the synergistic effect of $\alpha$-amylase and lipase catalysis the hydrolysis reaction leads to a much faster degradation of the construct. FTIR analysis has proven the hydrolytic effect of the enzymes over the materials, and it is noticeable the cleavage of the glycosidic bonds of starch and 
ester bonds of PCL by $\alpha$-amylase and lipase respectively. Contact angle analysis of the degraded SPCL scaffolds indicates that the hydrophilicity of the materials changes upon degradation.

DSC analysis has evidenced a decrease in crystallinity for longer degradation periods, as for shorter time points, the crystallinity of the samples increases due to the initial degradation of the amorphous regions of the polymer construct.

We can conclude, hereafter that SPCL scaffolds prepared by supercritical assisted phase inversion suffered bulk degradation, which is typically characterised by hydrolysis of chemical bonds in the polymer chain at the centre of the matrix, resulting in a highly porous material.

\section{Acknowledgments}

Ana Rita C. Duarte is grateful for financial support from Fundação para a Ciência e Tecnologia through the grant SFRH/BPD/34994/ 2007. The authors acknowledge Helena S. Azevedo for her help in the review of this paper.

\section{References}

[1] Ghosh S, Viana JC, Reis RL, Mano JF. The double porogen approach as a new technique for the fabrication of interconnected poly(L-lactic acid) and starch based biodegradable scaffolds. J Mater Sci Mater M 2007;18:185.

[2] Gomes ME, Holtorf HL, Reis RL, Mikos AG. Influence of the porosity of starchbased fibre mesh scaffolds on the proliferation and osteogenic differentiation of bone marrow stromal cells cultured in a flow perfusion bioreactor. Tissue Eng 2006;12:801.

[3] Salgado AJ, Coutinho OP, Reis RL, Davies JE. In vivo response to starch-based scaffolds designed for bone tissue engineering applications. J Biomed Mater Res A 2007;80A:983.

[4] Santos MI, Pashkuleva I, Alves CM, Gomes ME, Fuchs S, Unger RE, et al. Surface-modified 3D starch-based scaffold for improved endothelialization for bone tissue engineering. J Mater Chem 2009;19:4091.

[5] Boesel LF, Reis RL. A review on the polymer properties of hydrophilic, partially degradable and bioactive acrylic cements (HDBC). Prog Polym Sci 2008; 33:180.

[6] Malafaya PB, Elvira C, Gallardo A, San Roman J, Reis RL. Porous starch-based drug delivery systems processed by a microwave route. J Biomat Sci-Polym E 2001;12:1227.

[7] Malafaya PB, Stappers F, Reis RL. Starch-based microspheres produced by emulsion crosslinking with a potential media dependent responsive behaviour to be used as drug delivery carriers. J Mater Sci Mater M 2006;17:371.

[8] Marques AP, Reis RL, Hunt JA. Evaluation of the potential of starch-based biodegradable polymers in the activation of human inflammatory cells. J Mater Sci Mater M 2003;14:167.

[9] Azevedo HS, Reis RL. Understanding the enzymatic degradation of biodegradable polymers and strategies to control their degradation rate. In: Reis RL, Roman JS, editors. Biodegradable systems in tissue engineering and regenerative medicine. Boca Raton: CRC Press; 2005.

[10] Duarte ARC, Mano JF, Reis RL. Perspectives on: supercritical fluid technology for the preparation of $3 \mathrm{D}$ scaffolds for tissue engineering applications. J Bioactive Compat Polym; 2009.

[11] Reverchon E, Adami R, Cardea S, Porta GD. Supercritical fluids processing of polymers for pharmaceutical and medical applications. J Supercrit Fluids 2009; $47: 484$.

[12] Duarte ARC, Mano JF, Reis RL. Supercritical fluids in biomedical and tissue engineering applications: a review. Int Mater Rev 2009;54:214.
[13] Mooney DJ, Baldwin DF, Suh NP, Vacanti LP, Langer R. Novel approach to fabricate porous sponges of poly(D, L-lactic-co-glycolic acid) without the use of organic solvents. Biomaterials 1996;17:1417.

[14] Hutmacher DW. Scaffold design and fabrication technologies for engineering tissues - state of the art and future perspectives. J Biomat Sci-Polym E 2001; $12: 107$.

[15] Davies OR, Lewis AL, Whitaker MJ, Tai H, Shakesheff KM, Howdle SM. Applications of supercritical $\mathrm{CO} 2$ in the fabrication of polymer systems for drug delivery and tissue engineering. Adv Drug Deliv Rev 2008;60:373.

[16] Matsuyama H, Yano H, Maki T, Teramoto M, Mishima K, Matsuyama K. Formation of porous flat membrane by phase separation with supercritical CO2. J Memb Sci 2001;194:157.

[17] Reverchon E, Cardea S, Rappo ES. Production of loaded PMMA structures using the supercritical CO2 phase inversion process. J Memb Sci 2006;273:97.

[18] Reverchon E, Cardea S, Rappo ES. Membranes formation of a hydrosoluble biopolymer (PVA) using a supercritical CO2-expanded liquid. J Supercrit Fluids 2008;45:356.

[19] Temtem M, Casimiro T, Mano JF, Aguiar-Ricardo A. Preparation of membranes with poly sulfone/polycaprolactone blends using a high pressure cell specially designed for a $\mathrm{CO} 2$-assisted phase inversion. J Supercrit Fluids 2008;43:542.

[20] Duarte ARC, Mano JF, Reis RL. The role of organic solvent on the preparation of chitosan scaffolds by supercritical assisted phase inversion, J Supercrit Fluids, in press.

[21] Temtem M, Silva LMC, Andrade PZ, dos Santos F, da Silva CL, Cabral JMS, et al. Supercritical $\mathrm{CO} 2$ generating chitosan devices with controlled morphology. Potential application for drug delivery and mesenchymal stem cell culture. J Supercrit Fluids 2009;48:269.

[22] Duarte ARC, Mano JF, Reis RL. Preparation of starch-based scaffolds for tissue engineering by supercritical immersion precipitation. J Supercrit Fluids 2009; 49:279.

[23] Duarte ARC, Mano JF, Reis RL. Supercritical phase inversion of starch-poly ( $\varepsilon$-caprolactone) for tissue engineering applications. J Mater Sci Mater M 2010;21:533-40.

[24] vandeWitte P, Dijkstra PJ, vandenBerg JWA, Feijen J. Phase separation processes in polymer solutions in relation to membrane formation. J Memb Sci 1996;117:1.

[25] Reverchon E, Cardea S. PVDF-HFP membrane formation by supercritical CO2 processing: elucidation of formation mechanisms. Ind Eng Chem Res 2006; 45:8939.

[26] Azevedo HS, Gama FM, Reis RL. In Vitro assessment of the enzymatic degradation of several starch based biomaterials. Biomacromolecules 2003;4:1703.

[27] Balmayor ER, Tuzlakoglu K, Marques AP, Azevedo HS, Reis RL. A novel enzymatically-mediated drug delivery carrier for bone tissue engineering applications: combining biodegradable starch-based microparticles and differentiation agents. J Mater Sci Mater M 2008;19:1617.

[28] Martins AM, Pham QP, Malafaya PB, Sousa RA, Gomes ME, Raphael RM, et al. The role of lipase and alpha-amylase in the degradation of starch/poly (epsilon-caprolactone) fibre meshes and the osteogenic differentiation of cultured marrow stromal cells. Tissue Eng Part A; 2008.

[29] Pashkuleva I, Azevedo HS, Reis RL. Surface structural investigation of starchbased biomaterials. Macromol Biosci 2008;8:210.

[30] Pawlak A, Mucha M. Thermogravimetric and FTIR studies of chitosan blends. Thermochim Acta 2003;396:153.

[31] Huang S, Wu G, Chen S. Preparation of microporous poly(vinylidene fluoride) membranes via phase inversion in supercritical CO2. J Memb Sci 2007; 293:100.

[32] Huang MH, Li SM, Hutmacher DW, Coudane J, Vert M. Degradation characteristics of poly(epsilon-caprolactone)-based copolymers and blends. J Appl Polym Sci 2006;102:1681.

[33] Wang YM, Rodriguez-Perez MA, Reis RL, Mano JF. Thermal and thermomechanical behaviour of polycaprolactone and starch/polycaprolactone blends for biomedical applications. Macromol Mater Eng 2005;290:792.

[34] Crescenz V, Manzini G, Calzolar G, Borri C. Thermodynamics of fusion of polybeta-propiolactone and poly-epsilon-caprolactone - comparative analysis of melting of aliphatic polylactone and polyester chains. Eur Polym J 1972;8:449. 